\title{
GESTÃO DA SAÚDE PÚBLICA EM MINAS GERAIS SOB A ÓTICA DOS CONSELHOS GESTORES MUNICIPAIS ${ }^{1}$
}

\author{
Edson Arlindo Silva ${ }^{2}$ \\ Cláudia Souza Passador ${ }^{3}$
}

http://dx.doi.org/10.1590/1413-2311.207.83020

\section{RESUMO}

Os 13 Conselhos Municipais de Saúde das Mesorregiões de Planejamento em Gestão de Saúde do Estado de Minas Gerais é o foco deste artigo. Optou-se por analisar o desenho institucional dos conselhos municipais de saúde, a fim de verificar as normas que demarcaram a sua criação e o seu funcionamento, além das consequências do desenho institucional sobre o processo deliberativo com o auxílio da Técnica de Análise Documental. Durante as reuniões nos conselhos pesquisados, ocorreu a aplicação de Entrevista Semiestruturada e o levantamento de informações e dados oficiais. Os resultados evidenciam que a maioria dos conselhos estão instituídos legalmente, com previsão normativa quanto à pluralidade da composição, publicidade de suas reuniões e decisões, igualdade de oportunidade. As conclusões relevantes da pesquisa sinalizam que todo este movimento legal e normativo corrobora para garantir o funcionamento mínimo de determinado conselho de saúde, em regiões historicamente com pouco ou nenhum legado de "lutas" coletivas, baixo engajamento cívico e organização estrutural fragilizada em decorrência da baixa participação dos envolvidos e poucas ações efetivas em prol da transparência, fiscalização e controle social, particularmente no âmbito municipal.

\footnotetext{
${ }^{1}$ Recebido em 20/05/2018, aceito para publicação em 18/07/2018.

${ }^{2}$ Universidade Federal de Uberlândia (Uberlândia, MG, Brasil) - edsonarlindosilva@gmail.com

${ }^{3}$ Universidade de São Paulo (São Paulo, SP, Brasil) - cspassador@usp.br
} 
Palavras Chaves: Gestão. Conselho Municipal de Saúde. Processo Deliberativo. Desenho Institucional.

\title{
MANAGEMENT OF THE PUBLIC HEALTH IN THE STATE OF MINAS GERAIS UNDER THE VISION OF THE COUNCIL OF MUNICIPAL MANAGERS
}

\begin{abstract}
The Municipal Health Councils Poles of the Planning Mesoregions in Health Management in the state of Minas Gerais. Was opted to analyse the institutional picture of the municipal health councils, in order to verify the rules that distinguished its creation and its functioning beyond the consequences of the institutional framework about the decision process with the help of Document Analysis Technique. During the meetings in the studied councils, has occurred the application of semi--structured of interviews and the survey of official data and information. The results show that the majority of the councils are established rightfully, with normative prevision about the plurality of the composition, publicity of its meetings and decisions, equal opportunities. The relevant conclusions of the research suggests a all this normative and legal movement corroborates to ensure the minimum function of a specific health council, in historically regions with few or none legacy of collective "struggles", low civic engagement and weakened structural organization as a result of a low participation of the involved and few effective actions on behalf of the transparency, inspection and social control, particularly in the municipal context.
\end{abstract}

Keywords: Management. Municipal Health Council. Deliberative Process. Institutional Framework.

\section{GESTIÓN DE LA SALUD PÚBLICA EN MINAS GERAIS EN LA OPTICA DE LOS CONSEJOS GESTORES MUNICIPALES}

\section{RESUMEN}

Los 13 Consejos Municipales de Salud de las Mesorregiones de Planeamiento en Gestión de Salud del Estado de Minas Gerais. Se optó por analizar el diseño institucional de los consejos municipales de salud, a fin de verificar las normas que demarcaron su creación y su 
funcionamiento además de las consecuencias del diseño institucional sobre el proceso deliberativo con el auxilio de la Técnica de Análisis Documental. Durante las reuniones en los consejos pesquisados, ocurrió la aplicación de Entrevista Semiestructurado y el levantamiento de informaciones y datos oficiales. Los resultados evidencian que la mayoría de los consejos están instituidos de manera formal y legal, con previsión normativa cuanto a la pluralidad de la composición, publicidad de sus reuniones y decisiones, igualdad de oportunidad. Las conclusiones relevantes de la pesquisa señalan que todo este movimiento legal y normativo corrobora para garantizar el funcionamiento mínimo de determinado consejo de salud, en regiones históricamente con poco o ningún legado de "luchas" colectivas, bajo compromiso cívico y organización estructural fragilizada por consecuencia de la poca participación de los involucrados y pocas acciones efectivas en favor de la transparencia, fiscalización y control social, particularmente en el ámbito municipal.

Palabras-clave: Gestión. Consejo Municipal de Salud. Proceso Deliberativo. Diseño Institucional.

\section{INTRODUÇÃO}

A Constituição Federal de 1988 (CF-88) por meio de seus artigos definiu a participação social como necessária em algumas políticas específicas, abrindo espaço para a partilha de poder nas mais diferentes áreas, dentre elas saúde, assistência social, direitos da criança e do adolescente, infraestrutura urbana, segurança pública, direitos humanos, dentre outras relacionadas à Vida Social. Nesse sentido, desde o contexto da redemocratização do país - a partir da segunda metade da década de 1980 - e de maneira especial, após a celebração da CF-88 e da posterior legislação das políticas sociais, ocorreu à expansão de mecanismos de participação e controle da sociedade civil nas políticas públicas, o que resultou em um repertório amplo e heterogêneo de desenhos, processos deliberativos e alcance democrático (BRASIL et al., 2013).

Geralmente, como observado nos conselhos municipais de saúde pesquisados neste estudo, a expansão e a regulamentação dos mecanismos de participação e controle social se deu sob dois movimentos: Primeiro, pela ação direta do Governo Federal e do Congresso Nacional para que Estados/Distrito Federal e Municípios pudessem efetivar a operacionalização da lei vigente e criar tais mecanismos de maneira formal atrelando a esta 
condição o repasse de recursos federais para áreas estratégicas como Saúde, Segurança Pública, Educação e outras. Segundo, as reivindicações e pressões por parte de grupos organizados da Sociedade Civil, que viam nos mecanismos de participação e controle social uma oportunidade singular para fiscalizar, monitorar, atuar e decidir sobre recursos e políticas públicas de dimensões abrangentes (DAGNINO, 2002, TATAGIBA, 2004; FUKS; PERISSINOTTO; SOUZA, 2004).

Nesse sentido, observou-se que no decurso do presente século os espaços institucionais de participação e controle social, como são os casos exemplares dos Conselhos Municipais de Saúde, vêm se expandindo significativamente pelos três níveis da administração pública brasileira e se tornaram mecanismos formalmente institucionalizados na vida social dos munícipios brasileiros por meio da formulação, implementação e avaliação de políticas públicas em diversas áreas. Estudos recentes a respeito dos Mecanismos de Controle Social, como são os casos dos Conselhos Gestores de Políticas Públicas, sob a ótica de vários enfoques teóricos e realidades empíricas diversas (COELHO, 2006; AVRITZER, 2009; AGUIAR; SILVA; FERREIRA, 2015) vêm ganhando visibilidade nas ultimas décadas e tem contribuído para expor a realidade destes espaços institucionalizados de participação cidadã e exercício da democracia, por meio de seus desenhos institucionais, prerrogativas normativo-legais, ação comunicativa, engajamento cívico, modelos de gestão adotados, processos decisórios praticados e formas de participação/intervenção sociopolítica (DAHL, 1989; PUTNAM, 1993; O’DONNELL, 1994; HABERMAS, 1995; PATEMAN, 1999).

No contexto brasileiro, especialmente na área da gestão da saúde pública, a participação social é fundamentada nos princípios e nas diretrizes normativo-legais do Sistema Único de Saúde (SUS), prescritos na Constituição Federal de 1988 e nas Leis Orgânicas de Saúde, sendo os Conselhos Gestores e as Conferências de Saúde exemplos significativos de materialização destes espaços institucionalizados (FEDOZZI, 1998; JACOBI, 1990;). Desse modo, para que os conselhos cumpram seu papel institucional na formulação, controle, implementação e avaliação de políticas, assim como, na fiscalização da gestão da saúde, são necessárias normas e diretrizes que auxiliem os trabalhos destes importantes mecanismos de participação e controle social. Neste sentido, a Lei $\mathrm{n}^{\mathrm{o}} 8.142$ de 1990 e a Resolução no 453 de 2012, regem o funcionamento dos Conselhos Gestores de Políticas Públicas (TATAGIBA, 2002; COELHO, 2004).

Diante desse conhecimento acumulado, os autores notaram que o desenho institucional vem ganhando centralidade nas discussões sobre instituições deliberativas, uma vez que suas escolhas e variações produzem uma série de consequências para os resultados da 
participação. Neste interim, identificou-se que o desenho institucional tem sido tratado como um fator explicativo importante da dinâmica desses espaços. Estudos empíricos, focados nas regras de funcionamento de conselhos, mostram que as normas destas instituições participativas definem quem pode participar, quem tem direito a voz e voto, o que deve ser discutido, como deve ocorrer os debates e a tomada de decisões (DAGNINO, 2002; AVRITZER, 2008; SILVA, et al., 2014; AGUIAR, 2016). Um resultado comum destas pesquisas é que o desenho institucional impacta de forma decisiva os resultados da deliberação, uma vez que define a quantidade de participantes e os critérios para a inclusão, os formatos e a qualidade das deliberações, além da distribuição das informações entre os membros envolvidos no processo deliberativo (ABERS, 2000; FUNG, 2004).

Por outro lado, a importância teórica e prática do desenho institucional têm mostrado outros fatores relevantes decorrentes dos padrões sociais e culturais existentes na sociedade brasileira que potencializam os resultados desses espaços, como, por exemplo, a vontade política das autoridades administrativas (CUNHA, 2015), a densidade associativa (AVRITZER, 2009) a cultura política dos atores e seus recursos individuais e coletivos (MARQUES, 2010; FUKS; PERISSINOTTO; SOUZA, 2004) dentre outros fatores que podem comprometer o desempenho destes espaços e colocar em dúvida a sua real capacidade de produzir ações capazes de gerar reflexos na qualidade da gestão das políticas públicas, particularmente na área da saúde. Portanto nesta pesquisa em evidência de caráter teóricoempírico, foram feitas análises críticas pontuais das leis de criação e dos regimentos internos dos conselhos. Esta opção analítica se deu em face dos estudos de Avritzer (2009) e Faria e Ribeiro (2011), e que apontam para o potencial explicativo dos arranjos institucionais no que diz respeito à distribuição interna de cargos, aos critérios de composição e participação, além dos procedimentos de tomada de decisão.

Diante dessas limitações e possibilidades apresentadas surge a questão de pesquisa: Como são tomadas as decisões sobre políticas públicas em saúde no âmbito dos conselhos, sob a ótica dos princípios de deliberação e participação levando em consideração o desenho institucional predominante? Basicamente a questão central de pesquisa se desdobra em duas perguntas-chave, quais sejam: Sobre o que se decide? Quem decide dentro dos Conselhos Municipais Polos de Saúde de 13 macrorregiões do Estado de Minas Gerais?

Considerando a complexidade das decisões tomadas no âmbito dos conselhos de políticas públicas e a importância destas institucionalidades para a gestão pública, esse trabalho estabeleceu como objetivo principal analisar o processo decisório dos Conselhos Gestores de Políticas Públicas de Saúde sob a ótica dos princípios de participação e 
deliberação considerando principalmente seus desenhos institucionais vigentes. Especificamente pretendeu-se atingir os seguintes objetivos: a) Analisar os papéis desempenhados pelos conselheiros nas tomadas de decisões sobre políticas públicas em saúde em Minas Gerais; b) Compreender como são executadas as funções delegadas aos conselheiros; c) Analisar como são pensadas e praticadas as participações dos membros representantes dos conselhos. A partir do contexto apresentado este artigo encontra-se estruturado em seis seções, incluindo a introdução, que são apresentadas e discutidas criticamente neste estudo sobre a temática - "Conselhos Gestores de Políticas Públicas em Saúde" - nos âmbitos municipal e regional.

\section{CONSELHOS GESTORES E DESENHOS INSTITUCIONAIS}

O desenho institucional vem ganhando destaque nas discussões sobre as instituições deliberativas. Autores como Avritzer (2009), Cunha (2015) e Aguiar (2016), destacam a importância do desenho institucional para a efetividade, a equidade e a expansão da participação e da deliberação, já que, é ele que oferece as regras para a sua atuação. Considerando o desenho institucional como o conjunto de regras que estruturam uma determinada forma institucional e partindo da premissa de que os desenhos não são neutros, suas escolhas e suas variações podem influenciar diretamente os resultados da participação política, pois, é o tipo de desenho que define quem está participando, quais assuntos são deliberados, como as discussões são feitas, qual a frequência de encontros entre os participantes, modelos de gestão e processos decisórios (ABERS, 2000; FUNG, 2004; WENDHAUSEN e CARDOSO, 2007).

\section{Quadro 1 - Produções Nacionais Sobre Conselhos Gestores, Participação e Democracia}

\begin{tabular}{|l|l|}
\hline \multicolumn{2}{|c|}{ AUTORES NACIONAIS } \\
\hline \multicolumn{1}{|c|}{ AUTOR } & \multicolumn{1}{c|}{ DESCRIÇÃO SUCINTA } \\
\hline JACOBI (1989; 1990) & Investigou a relação entre políticas públicas, movimentos sociais e saúde no Brasil. \\
\hline BRASIL (1990) & $\begin{array}{l}\text { A Lei define os Conselhos Gestores de Políticas Públicas como instâncias formais } \\
\text { de participação social além de estabelecer a composição, o caráter e o papel } \\
\text { desempenhado por cada uma dessas instâncias. }\end{array}$ \\
\hline FEDOZZI (1998) & Orçamento Participativo \\
\hline DAGNINO (2002) & $\begin{array}{l}\text { Analisou a relação entre Sociedade Civil, Participação Social e os Conselhos } \\
\text { Gestores de Políticas Públicas. }\end{array}$ \\
\hline $\begin{array}{l}\text { TATAGIBA (2002; } \\
\text { 2004) }\end{array}$ & $\begin{array}{l}\text { Investigou a institucionalização da participação democrática em espaços } \\
\text { institucionalizados como os conselhos municipais no Estado de São Paulo. }\end{array}$ \\
\hline & $\begin{array}{l}\text { Para este autor o sucesso dos processos participativos está na articulação entre o } \\
\text { desenho institucional, a organização da sociedade civil e a vontade política de }\end{array}$ \\
\hline
\end{tabular}




\begin{tabular}{|c|c|}
\hline $\begin{array}{l}\text { AVRITZER (2003; } \\
\text { 2008; 2009; 2010) }\end{array}$ & $\begin{array}{l}\text { implementar desenhos participativos. Apresenta três desenhos participativos, } \\
\text { sendo chamados pelo autor de Bottom-Up Designs (Desenhos de Baixo para } \\
\text { Cima), os Power Sharing Designs (Desenhos com Partilhamento de Poder) e os } \\
\text { Ratification Designs (Desenhos de Ratificação). }\end{array}$ \\
\hline $\begin{array}{l}\text { FUNG e WRIGHT } \\
(2003)\end{array}$ & $\begin{array}{l}\text { Destacam a importância do desenho para a efetividade, a equidade e a expansão da } \\
\text { participação e da deliberação, já que, é ele que oferece as regras para a sua } \\
\text { atuação. }\end{array}$ \\
\hline FUNG (2004) & Desenho institucional incide sobre o caráter da participação e da deliberação. \\
\hline LAVALLE et al. (2004) & $\begin{array}{l}\text { Potencial explicativo dos arranjos institucionais no que diz respeito à distribuição } \\
\text { interna de cargos. }\end{array}$ \\
\hline $\begin{array}{l}\text { FUKS, } \\
\text { PERISSINOTTO e } \\
\text { SOUZA (2004) }\end{array}$ & Cultura política dos atores e seus recursos individuais e coletivos \\
\hline FARIA (2007) & $\begin{array}{l}\text { Evidenciou os critérios de composição e participação nos conselhos gestores de } \\
\text { políticas públicas, além dos procedimentos de tomada de decisão. }\end{array}$ \\
\hline ALMEIDA & $\begin{array}{l}\text { Conhecer as condições normativas de cada conselho e seu potencial democrático e } \\
\text { deliberativo. }\end{array}$ \\
\hline MARQUES (2010) & Reflexos na deliberação e qualidade da gestão das políticas públicas. \\
\hline $\begin{array}{l}\text { FARIA e RIBEIRO } \\
\text { (2011) }\end{array}$ & $\begin{array}{l}\text { Estudos empíricos focados nas regras de funcionamento de conselhos, mostram } \\
\text { que as normas destas instituições participativas definem quem pode participar, } \\
\text { quem tem direito a voz e voto, o que deve ser discutido, como deve ocorrer os } \\
\text { debates e a tomada de decisões. }\end{array}$ \\
\hline COELHO (2009) & $\begin{array}{l}\text { Investigou o Sistema Único de Saúde (SUS) embasado nos princípios de } \\
\text { Universalidade, Equidade dos Serviços de Saúde e Participação Popular. }\end{array}$ \\
\hline LOPES (2014) & $\begin{array}{l}\text { Compete ao Conselho questões de formulação, avaliação e controle de políticas } \\
\text { públicas, fiscalização do poder executivo, controle do orçamento de saúde e gestão } \\
\text { do Fundo Municipal de Saúde, dentre outras competências. }\end{array}$ \\
\hline SILVA, et al., (2014) & $\begin{array}{l}\text { Para que o conselho consiga alcançar o objetivo para o qual foi criado e para que o } \\
\text { desenho institucional seja devidamente delineado, existe um conjunto de normas } \\
\text { que o cercam, trazendo questões relativas a seu funcionamento, a sua organização } \\
\text { e suas competências. }\end{array}$ \\
\hline $\begin{array}{l}\text { AGUIAR, SILVA e } \\
\text { FERREIRA (2015) }\end{array}$ & $\begin{array}{l}\text { Pesquisaram os efeitos das instituições participativas sobre a gestão pública } \\
\text { municipal. }\end{array}$ \\
\hline CUNHA (2015) & $\begin{array}{l}\text { Vontade política das autoridades administrativas e o desenho institucional como } \\
\text { conjunto de regras que estruturam uma determinada forma institucional, partindo } \\
\text { da premissa de que os desenhos não são neutros, suas escolhas e suas variações } \\
\text { podem influenciar diretamente os resultados da participação política. }\end{array}$ \\
\hline
\end{tabular}

Fonte: elaborado pelos autores com resultados de revisão de literatura.

Os Quadros 1 e 2 expõem os principais pesquisadores e pesquisadoras, nacionais e internacionais, que investigaram e ainda investigam em realidades diversas, o funcionamento, a participação social, as estruturas institucionais, os modelos democráticos adotados e o compartilhamento da gestão no contexto da atuação dos Mecanismos de Fiscalização e Controle Social, com especial destaque para os Conselhos Gestores de Políticas Públicas em Saúde, objeto de estudo desta pesquisa. 


\section{Quadro 2- Produções Internacionais Sobre Conselhos Gestores, Participação e Democracia}

\begin{tabular}{|c|c|}
\hline \multicolumn{2}{|r|}{ AUTORES INTERNACIONAIS } \\
\hline AUTOR & DESCRIÇÃO SUCINTA \\
\hline TOCQUEVILLE (1835) & $\begin{array}{l}\text { Abordou elementos da democracia na América com foco nos Estados Unidos do } \\
\text { início do século XIX, destacando em seus estudos as virtudes e mazelas do povo } \\
\text { norte-americano. Em um primeiro momento teve interesse em compreender o } \\
\text { funcionamento do sistema prisional dos EUA, tendo acesso também às } \\
\text { informações sobre os aspectos da sociedade norte americana, incluindo a sua } \\
\text { economia e o seu sistema político, único no mundo até então. }\end{array}$ \\
\hline SCHUMPETER (1942) & $\begin{array}{l}\text { Investigou a relação entre Capitalismo, Democracia e Socialismo no contexto } \\
\text { econômico mundial da Segunda Guerra do século XX. }\end{array}$ \\
\hline MARSHALL (1950) & Interfaces entre cidadania e classe social. \\
\hline PATEMAN (1970) & Estudou as formas de participação em modelos democráticos. \\
\hline BOBBIO (1988) & $\begin{array}{l}\text { Implicações teóricas entre Estado Democrático de Direito, Sociedade Civil e } \\
\text { Política. }\end{array}$ \\
\hline KEANE (1988) & Pesquisou as relações entre Sociedade Civil, Estado e Democracia. \\
\hline $\begin{array}{l}\text { RUESCHEMEYER, e } \\
\text { STEPHENS (1992) }\end{array}$ & Investigaram a relação entre desenvolvimento, capitalismo e democracia. \\
\hline PUTNAM (1993) & Engajamento cívico, cidadania, participação e democracia. \\
\hline HUNTINGTON (1994) & Investigou os processos democráticos em países latinos americanos. \\
\hline O’DONNELL (1994) & Estudou a relação entre Estado e Democracia na América Latina. \\
\hline HABERMAS (1995) & $\begin{array}{l}\text { Esfera pública, ação comunicativa, modelos normativos de democracia, processos } \\
\text { deliberativos e direito. }\end{array}$ \\
\hline OXHORN (1995) & $\begin{array}{l}\text { Foco no modelo tripartite da sociedade civil, que também pode ser identificada em } \\
\text { outras tradições do pensamento social, entre elas a diferenciação entre sociedade } \\
\text { civil, sociedade política e Estado em Gramsci. }\end{array}$ \\
\hline MIGDAL (2001) & Estado Democrático de Direito e Sociedade Civil. \\
\hline TILLY (2004) & Investigação sobre modelos democráticos no contexto Europeu. \\
\hline $\begin{array}{l}\text { FEINBERG, } \\
\text { WAISMAN e } \\
\text { ZAMOSC (2006) }\end{array}$ & $\begin{array}{l}\text { Concebeu a sociedade civil como uma instância autônoma de produção de } \\
\text { solidariedade social. }\end{array}$ \\
\hline URBINATI (2006) & Investigação sobre a democracia representativa. \\
\hline YOUNG (2006) & Trata-se dos aspectos de inclusão em ambientes democráticos. \\
\hline SHAH (2007) & Orçamento Participativo. \\
\hline $\begin{array}{l}\text { PERUZZOTTI e } \\
\text { SELEE (2009) }\end{array}$ & $\begin{array}{l}\text { Trata da participação social como mecanismo de inovação em modelos } \\
\text { democráticos. }\end{array}$ \\
\hline WAMPLER (2014) & $\begin{array}{l}\text { Estudou a relação entre conselhos gestores de politicas públicas, participação } \\
\text { democrática e contextos políticos no Brasil. }\end{array}$ \\
\hline
\end{tabular}

Fonte: elaborado pelos autores com resultados de revisão de literatura.

Neste sentido, tendo em vista o retrato da Revisão de Literatura sobre a temática pesquisada, é possível afirmar, seguindo o pensamento e as interseções comuns de Fung (2004), Avritzer (2009) e Cunha e Theodoro (2015), que o desenho institucional adotado pelos Conselhos Gestores de Políticas Públicas pode incorrer em quatro aspectos abrangentes, quais sejam: 1) no caráter da participação e da deliberação; 2) na aferição de informações e 
transformação individual; 3) no controle popular e no desempenho do Estado; e 4) nos efeitos políticos.

Reforçando esta lógica de pensamento em regimes democráticos, Dahl (1989), Putnam (1993), Huntington (1994) e Habermas (1995) acreditam na transformação social, já que para eles, as arenas deliberativas funcionam como "escolas de democracia", lugar onde os indivíduos adquirem as habilidades da cidadania. Nesta mesma direção Avritzer (2009) argumenta que a escolha do desenho institucional contribui para elevar o controle social, ou seja, o desenho abre espaço para que os cidadãos possam fiscalizar as ações políticas de seus representantes e avaliar o comportamento do Estado. No entanto, é igualmente importante destacar aqueles que acreditam (DAGNINO, 2002; TATAGIBA, 2004; FARIA; RIBEIRO, 2011; SILVA et al., 2014; AGUIAR, 2016) que não somente o desenho institucional influencia os resultados da deliberação, mas existem outros fatores e contextos que podem afetar esses resultados.

O sucesso dos processos participativos está na articulação entre o desenho institucional, a organização da sociedade civil e a vontade política de implementar desenhos institucionais participativos legítimos. Nesta mesma direção, Avritzer (2009) trás que os fatores culturais e políticos influenciam a escolha do próprio desenho institucional. Nos modelos de desenhos institucionais presentes em espaços de participação institucionalizados os atores da sociedade civil não participam do processo decisório, mas são chamados a referendá-lo publicamente, como exemplo, podem ser citados os Planos Diretores Municipais e os Orçamentos Participativos. Para Wendhausen e Cardoso (2007), ao se comparar os desenhos institucionais predominantes, nota-se que eles se diferenciam em pelo menos três aspectos, que seriam: Primeiro, a iniciativa na criação do desenho; Segundo, o modo como a Sociedade Civil se organiza e; Terceiro, a pretensão política do governo em implementar a participação social. Assim, esses aspectos se expressam de forma diferenciada na configuração dos desenhos institucionais o que irá refletir na sua capacidade democratizante e no nível de dependência do sistema político.

\section{A CONSTRUÇÃO DO SISTEMA ÚNICO DE SAÚDE NO BRASIL}

Ao considerar o histórico brasileiro relacionado às políticas públicas de saúde, percebe-se um maior movimento em direção às melhores condições sanitárias para a população apenas no início da Era Vargas em 1930. Até então, poucas ações aleatórias buscavam a qualidade de vida para a população, como é o caso da "Revolta da Vacina" 
(1904) ou as lutas pelo controle das epidemias, principalmente nas regiões portuárias que afetavam diretamente a economia brasileira. Assim, pode-se afirmar que a construção do Sistema Único de Saúde (SUS) no Brasil foi um processo que se iniciou com as primeiras políticas de saúde em meados de 1930, no entanto, não apenas de ações do Estado, já que a Sociedade Civil organizada buscou, durante os anos que precederam a Criação do SUS, por melhores condições de Saúde e por participação nas decisões sobre políticas públicas e recursos para a área da saúde (JACOBI, 1989; COELHO, 2006).

Durante um longo período da evolução da saúde pública no Brasil (1930 a 1991) quando o SUS foi criado e institucionalizado -, a sociedade brasileira passou por experiências democráticas e regimes autoritários até chegar a um Estado Democrático de Direito, tendo como marco a promulgação da Constituição Federal de 1988. A este fato, confirma-se a situação da saúde pública brasileira no referido período já que, podia ser considerada desigual e cercada por interesses das elites (JACOBI, 1989; FUKS, 2004). Esta situação pode ser um dos elementos motivadores dos movimentos populares que se formaram no interior do país na busca pelos direitos da população em relação ao setor de saúde e pela reforma sanitária. Devido a estes movimentos, os processos participativos começaram a sobressair na sociedade brasileira.

No entanto, o Estado burocrático-autoritário configurado pelo governo militar fez com que essas práticas participativas recuassem, como exemplo, até mesmo as Conferências Nacionais de Saúde, caracterizadas por ser um espaço aberto para participação, durante este governo, foram transformadas quase que em um encontro técnico para decisões políticas de saúde (LIMA et al., 2005). Em 1979 a Câmara dos Deputados realizou o I Simpósio sobre Política Nacional de Saúde, onde os pensadores críticos oposicionista-reformistas - formados por intelectuais e pesquisadores representantes da sociedade civil - apontaram a crise do sistema de saúde do país, bem como a necessidade de democratização da sociedade. Foram apresentadas neste evento as primeiras diretrizes idealizadas para a formulação de um Sistema de Saúde Unificado (JACOBI, 1989; COELHO, 2006).

Em 1985, inicia-se a transição de um regime de exceção para um regime com aspirações democráticas. No ano seguinte ocorreu a VIII Conferência Nacional de Saúde com a participação de mais de 5.000 pessoas. Neste evento, dentre as principais diretrizes idealizadas, podem ser citadas: 1) Afirmação do principio da participação das entidades representativas na formulação de políticas e no planejamento, gestão, execução e avaliação das ações de saúde; 2) A Constituição de um novo Conselho Nacional de Saúde, incluindo 
além da esfera governamental, movimentos populares, e; 3) A formação de conselhos de saúde, municipais, regionais e estaduais (FALEIROS et al. 2006).

As Conferências Nacionais de Saúde merecem ser destacadas. Como observado, foi a partir da VIII Conferência que os Conselhos Gestores de Políticas Públicas de Saúde começaram a se originar, no entanto, as discussões institucionalizadas de saúde já haviam começado em 1941 com a I Conferência Nacional de Saúde. Em 1992, a IX Conferencia Nacional de Saúde enfatizou a democratização e o fortalecimento dos conselhos, sendo aprovada também em 1992, legislação específica com as recomendações para a criação e funcionamento dos Conselhos Estaduais e Municipais de Saúde e suas principais competências (LIMA et al., 2005; FALEIROS et al., 2006). Esta resolução definiu o Conselho Gestor de Saúde como:

O órgão ou instância colegiada de caráter permanente e deliberativo, em cada esfera de governo, integrante da estrutura básica da Secretaria ou Departamento de Saúde dos Estados e Munícipios, com composição, organização e competência fixada em lei. O Conselho consubstancia a participação da sociedade organizada na administração do Sistema de Saúde, propiciando o controle social desse sistema (BRASIL, 1992, p. 1).

Com caráter deliberativo, o poder dos conselhos vai além das discussões consultivas e de opinião em relação à gestão de saúde, existindo assim a possibilidade de intervenção no setor. Os conselhos devem efetivamente atuar na formulação de estratégias e no controle das políticas públicas de saúde. De acordo com Fleury et. al. (2010) este novo modelo de gestão de saúde é constituído por um conjunto de atores sociais, instituições e instâncias que compõem os processos deliberativos, de responsabilização e prestação de contas, além da capacidade de formular e executar políticas municipais de saúde. Em 2003, com o acumulo de experiência do "Controle Social da saúde e reiteradas demandas de Conselhos Estaduais e Municipais referentes às propostas de composição, organização e funcionamento dos conselhos de Saúde" (BRASIL, 2003, p. 3), foram aprovadas novas diretrizes para o funcionamento dos conselhos frente às principais contingencias já vivenciadas e com um desenho institucional melhor estruturado, sendo criada então a Resolução 333 de 2003. Em 2012, a Resolução 453 foi promulgada em substituição a Resolução 333. A lei definiu a saúde "como um direito de todos os cidadãos e como um dever do Estado", além de determinar a criação de um sistema de saúde pública, o Sistema Único de Saúde (SUS) 
embasado nos princípios de universalidade, equidade dos serviços de saúde e participação popular (COELHO, 2004).

Segundo informações do Instituto Brasileiro de Geografia e Estatística (IBGE, 2018) em 2014 99,7\% dos municípios possuíam conselho municipal de saúde, já na esfera estadual o conselho estava presente em todas as unidades estaduais. A pesquisa também constatou que dos 5.570 municípios brasileiros, 4.956, ou seja, 88,9\% realizaram conferências de saúde, cumprindo a determinação da Lei no 8.142 de 28 de dezembro de 1990.

Os conselhos de saúde são compostos por cidadãos representantes dos usuários do SUS, profissionais da área da saúde, prestadores de serviços de saúde e gestores públicos. Funcionam como órgão de instância colegiada e deliberativa e tem por finalidade a formulação e o controle da execução da política municipal de saúde, inclusive nos aspectos econômicos e financeiros, nas estratégias e na promoção do processo de controle social em toda sua amplitude, no âmbito dos setores públicos e privados. São espaços abertos onde os participantes apresentam propostas e reivindicações às secretarias de saúde e ajudam a definir prioridades e políticas para o setor de saúde (COELHO, 2006).

Desse modo, para que o conselho consiga alcançar o objetivo para o qual foi criado e para que o desenho institucional seja devidamente delineado, existe um conjunto de normas que o cercam, trazendo questões relativas a seu funcionamento, a sua organização e suas competências (SILVA, et al., 2014). No âmbito dos Conselhos Municipais de Saúde, as principais normas existentes são: a Lei no 8.142 de 1990; a Resolução no 453 de 2012, além do regimento interno do conselho. A Lei $\mathrm{n}^{\circ} 8.142 / 90$ veio para complementar a Lei $\mathrm{n}^{\circ}$ 8.080/90 em decorrência dos vetos efetuados pelo presidente da República daquela época, Fernando Collor (1990-1991). Ela dispõe sobre as transferências intergovernamentais de recursos financeiros na área da saúde e sobre a participação da comunidade na gestão do SUS por meio da criação das conferências e dos conselhos de saúde. A Lei define esses espaços como instâncias formais de participação social além de estabelecer a composição, o caráter e o papel desempenhado por cada uma dessas instâncias (BRASIL, 1990).

A Resolução $n^{0} 453$ é dividida em cinco diretrizes. A primeira trás a definição do conselho de saúde como:

Uma instância colegiada, deliberativa e permanente do Sistema Único de Saúde (SUS) em cada esfera de Governo, integrante da estrutura organizacional do Ministério da Saúde, da Secretaria de Saúde dos Estados, do Distrito Federal e dos Municípios, com composição, 
organização e competência fixadas na Lei n. 8.142/90 (BRASIL, 2012, p. 1).

Ainda na primeira diretriz, a resolução menciona a possibilidade do surgimento de conselhos regionais, conselhos locais, conselhos distritais de saúde, incluindo os conselhos dos distritos sanitários especiais indígenas. A segunda diretriz se refere à criação e reformulação do conselho, em que diz que a criação dos conselhos de saúde é instituída por Lei Federal, Estadual, do Distrito Federal e Municipal, obedecendo a Lei n. 8.142/90. Essa diretriz ainda trás que o Poder Executivo deverá acolher as demandas da população aprovadas nas Conferências de Saúde, e em consonância com a legislação. A terceira diretriz diz respeito à organização dos conselhos destacando a composição paritária de usuários em relação ao conjunto dos demais segmentos representados. Esta diretriz ainda apresenta a forma de representatividade dos membros do conselho e reafirma também a importância dos usuários do SUS nos espaços deliberativos, já que, define que 50\% dos membros devem ser desta área. Os outros 50\% são representantes de entidades de trabalhadores da saúde e membros representantes do Governo (25\% das vagas para cada setor). Essa diretriz ainda trás a autonomia de atuação dos conselhos ao colocar que "a participação do Poder Legislativo e Judiciário não cabe nos conselhos de saúde, em face da independência entre os poderes" (BRASIL, 2012, p. 3). Em relação à estrutura e funcionamento do conselho, a quarta diretriz confirma o dever do Governo frente ao conselho de garantir a referida autonomia do espaço deliberativo para o pleno funcionamento do conselho, sendo que "as três esferas de Governo garantirão autonomia administrativa para o pleno funcionamento do conselho de saúde, dotação orçamentária, autonomia financeira e organização da secretaria-executiva com a necessária infraestrutura e apoio técnico" (BRASIL, 2012, p. 4). Por último, a quinta diretriz trás as competências dos conselhos, que podem ser apontadas como a finalidade da existência do conselho, o porquê da criação deste espaço já que definem as áreas de atuação do conselho. São as competências estabelecidas na Resolução que geram a construção da agenda dos conselhos municipais, e consequentemente, as medidas que devem ser tomadas por eles.

Dessa forma, os estudos que propõem uma análise do desenho institucional e das normas que regulam os conselhos (ABERS, 2000; TATAGIBA, 2002; FUKS, 2004; AVRITZER, 2008; FARIA e RIBEIRO, 2011; SILVA et al., 2014; LIMA, 2014; AGUIAR, 2016;) têm destacado regras levantadas a partir de documentos específicos que regulam o funcionamento dessas instituições, quais sejam: as leis de criação e de alteração dos conselhos e seus regimentos internos, pois, esses são documentos que possibilitam conhecer as condições normativas de cada conselho e seu potencial democrático e deliberativo. 


\section{PERCURSO METODOLÓGICO}

Partindo do pressuposto de que o objetivo principal da pesquisa realizada foi analisar o processo decisório dos Conselhos Gestores de Políticas Públicas de Saúde sob a ótica do processo decisório deliberativo, considerando principalmente os desenhos institucionais vigentes, as normas e o funcionamento dos Conselhos Municipais de Saúde em 13 Macrorregiões de Planejamento Estratégico em Saúde do Estado de Minas Gerais, o estudo classificou-se quanto à abordagem, qualitativa, e quanto ao caráter, descritivo (VERGARA, 2015). O detalhamento da configuração institucional dos conselhos adveio da Técnica de Análise Documental, que de acordo com Gil (2007) é constituída pelo exame de materiais que ainda não receberam um tratamento analítico ou que podem ser reexaminados com vistas a uma interpretação nova ou complementar.

Assim, os documentos selecionados para a análise foram às leis de criação e alteração, além do regimento interno dos conselhos que foram comparados a Lei $n^{\circ}$ 8.142/1990 e a Resolução no 453/2012. De acordo com Almeida e Cunha (2011), as leis de criação e os regimentos internos retratam, por meio de suas normas, o desenho institucional dos conselhos municipais de saúde e desta forma, oferece um conjunto vasto de dados, informações e reflexões críticas que nos permitem avaliar o quanto estas novas institucionalidades estão aptas a cumprir as expectativas que motivaram suas criações e funcionamento. Os documentos selecionados para o estudo passaram pelo processo de Análise Documental, processo semelhante à da Técnica de Análise de Conteúdo. Segundo Bardin (2011), o desenvolvimento das Técnicas Documentais tem se mantido relativamente discreto no campo científico. Define ainda a Análise Documental como "uma operação ou um conjunto de operações visando representar o conteúdo de um documento sob uma forma diferente da original, a fim de facilitar, num estado ulterior, a sua consulta e referenciação" (BARDIN, 2011, p. 51). Essa técnica permite que um documento primário se transforme em um documento secundário.

Dentre as várias regras dos conselhos municipais de saúde possíveis de serem analisadas, foram destacadas aquelas apontadas como relevantes no estudo de Faria (2000), pois, acredita-se que elas possibilitam avaliar o potencial em relação à capacidade de inclusão e democratização desses espaços. As categorias e seus respectivos Fatores Analíticos são: Organização Interna (Fatores Analíticos: Frequência das reuniões; Número de membros; Paridade entre os membros; Presença de estrutura organizacional; Mandato da mesa diretora e dos conselheiros); Regras do Processo Deliberativo (Fatores Analíticos: Proposição de 
pauta; Quem pode introduzir ponto de pauta; Direito de falas de atores externos; Formas de votação); Composição (Fatores Analíticos: Quem pode presidir o conselho; Forma de seleção dos conselheiros da sociedade civil; Previsão de categorias de usuários; Entidades previstas dos usuários). Essas Categorias e seus Fatores Analíticos nortearam as discussões e a exposição dos resultados em torno das atas, regimentos, desenhos institucionais, entrevistas semiestruturadas (realizadas entre agosto de 2017 a março de 2018) e teorias utilizadas no decurso da pesquisa empreendida (FARIA, 2000).

Assim como Unidade de Análise de Investigação Científica têm-se os Conselhos Municipais de Saúde de Minas Gerais, mais especificamente os conselhos de saúde polos das 13 Macrorregiões de Planejamento Estratégico em Saúde, segundo divisão territorial oficial da Secretaria de Estado de Saúde de Minas Gerais (SES/MG). Na impossibilidade de aprofundar os estudos em todos os 853 municípios mineiros que compõem as macrorregiões, optou-se pelos Municípios Polos de cada macrorregião, sendo eles: Barbacena, Belo Horizonte, Diamantina, Divinópolis, Governador Valadares, Juiz de Fora, Montes Claros, Patos de Minas, Poços de Caldas, Ponte Nova, Teófilo Otoni, Uberlândia e Uberaba (SES/MG, 2018).

Em complemento à Análise Documental, foram realizadas pontuais reuniões e entrevistas semiestruturadas com conselheiros e conselheiras representantes do governo, dos trabalhadores da Saúde, prestadores de serviços e usuários do SUS, objetivando aprofundar questões que foram observadas na Técnica de Análise Documental e identificar especificidades de cada um dos conselhos estudados. A partir da análise da natureza desta investigação, verifica-se que ela converge para um estudo multicasos, pois, trata em profundidade situações particulares (BRUYNE, HERMAN; SCHOUTHEETE, 1991) e descreve mais de um sujeito, organização ou evento (GODOY, 1995).

\section{RESULTADOS E DISCUSSÕES}

Ao analisar a definição dos conselhos a partir do regimento das instituições em análise, verificou-se que cada um trouxe um conceito diferente. Apesar disso, foi possível identificar algumas características comuns entre eles como deliberativa, normativa e fiscalizadora. Assim, todas as definições trouxeram de forma explícita o caráter deliberativo e permanente do conselho. Algumas definições além do caráter deliberativo trouxeram os caráter normativo e fiscalizador. Vale destacar que o conselho de saúde de Barbacena foi o

que trouxe uma definição mais completa do que seria conselho e, ainda, foi à única 
instituição que trouxe o caráter consultivo do conselho em sua definição. Como característica comum a alguns casos, constatou que algumas definições explicitaram a composição, funcionamento e desenho institucional do conselho.

No que se refere ao ano de constituição dos conselhos estudados, ao analisar cronologicamente a lei de criação, percebeu que estes surgiram na década de 1990. Dentre os conselhos, oito deles foram criados no ano de 1991, somente os conselhos de Juiz de Fora e Uberaba foram criados um ano depois em 1992. Os conselhos estudados, portanto, foram criados, no primeiro momento logo após a promulgação da Lei Orgânica de Saúde $n^{\circ}$ 8.142, compondo cerca de $84 \%$ dos 853 municípios mineiros que instituíram seus conselhos municipais de saúde até o ano de 1999 (SES/MG e IBGE, 2018).

Conforme apresentado no embasamento teórico, em relação à diretriz constitucional da participação da comunidade no SUS, a Lei nº 8.142 de 1990 previu a criação de conselhos de saúde e conferências para compor as instâncias institucionalizadas de participação social no âmbito do SUS nas três esferas do governo (TATAGIBA, 2002). Como a lei dispõe sobre as transferências intergovernamentais de recursos financeiros na área da saúde, que se dá por meio da aprovação dos conselhos, nota-se uma correlação entre a data de criação desses espaços legitimamente institucionalizados e a regulamentação da exigência. A Tabela 1 mostra a distribuição dos gastos com a saúde pública em Minas Gerais ao longo desta década.

Tabela 1 - Panorama da Distribuição dos Gastos com Saúde Pública em Minas Gerais (2011-2018)

\begin{tabular}{|c|c|c|c|c|c|c|c|c|c|}
\hline \multicolumn{10}{|c|}{ Valores em Reais (R\$) } \\
\hline$\frac{\underline{G}}{\underline{\underline{Z}}}$ & 2011 & 2012 & 2013 & 2014 & 2015 & 2016 & 2017 & 2018 & ֻ \\
\hline 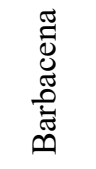 & $\begin{array}{c}55.731 .7 \\
18,98\end{array}$ & $\begin{array}{c}52.550 .4 \\
78,21\end{array}$ & $\begin{array}{c}50.917 .2 \\
50,61\end{array}$ & $\begin{array}{c}62.557 .4 \\
47,03\end{array}$ & $\begin{array}{c}73.318 .2 \\
99,05\end{array}$ & $\begin{array}{c}49.356 .6 \\
06,40\end{array}$ & $\begin{array}{c}54.249 .5 \\
07.179,9 \\
8\end{array}$ & $\begin{array}{l}7.576 .89 \\
4.712,43\end{array}$ & $\begin{array}{c}62.170 \\
833.69 \\
2,69\end{array}$ \\
\hline 을 $\frac{0}{\tilde{0}}$ & $\begin{array}{l}2.173 .83 \\
5.194,14\end{array}$ & $\begin{array}{l}1.148 .15 \\
6.491,68\end{array}$ & $\begin{array}{l}1.229 .33 \\
3.975,06\end{array}$ & $\begin{array}{l}1.359 .68 \\
6.250,09\end{array}$ & $\begin{array}{l}1.451 .47 \\
5.962,06\end{array}$ & $\begin{array}{l}1.343 .08 \\
1.878,40\end{array}$ & $\begin{array}{l}1.553 .75 \\
2.573,04\end{array}$ & $\begin{array}{c}278.505 \\
323,51\end{array}$ & $\begin{array}{c}10.537 \\
827.64 \\
7,98\end{array}$ \\
\hline 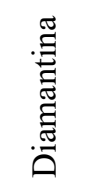 & $\begin{array}{c}5.335 .29 \\
6,92\end{array}$ & $\begin{array}{c}5.255 .96 \\
0,22\end{array}$ & $\begin{array}{c}5.940 .99 \\
4,50\end{array}$ & $\begin{array}{c}5.426 .25 \\
0,91\end{array}$ & $\begin{array}{c}6.416 .79 \\
0,66\end{array}$ & $\begin{array}{c}5.742 .28 \\
7,26\end{array}$ & $\begin{array}{c}18.455 .4 \\
00,01\end{array}$ & $\begin{array}{c}8.434 .04 \\
6,88\end{array}$ & $\begin{array}{c}61.007 \\
027,36\end{array}$ \\
\hline
\end{tabular}




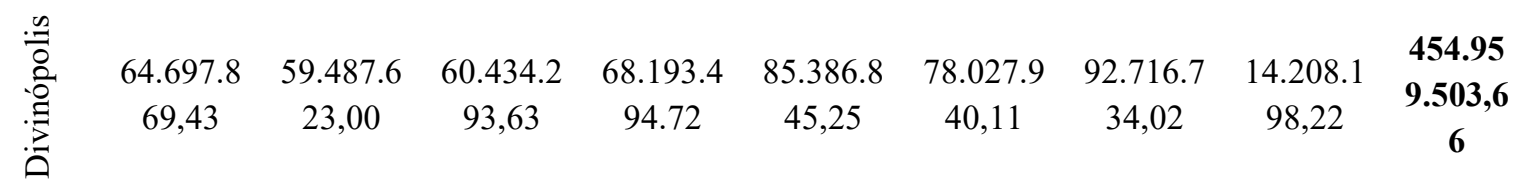

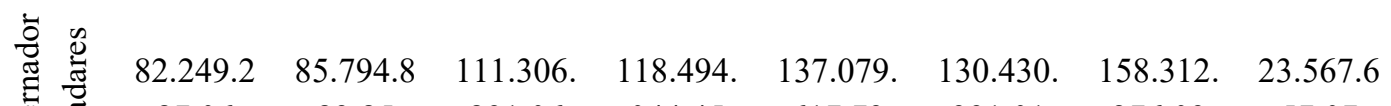
$\begin{array}{llllllll}87,06 & 83,85 & 891,06 & 044,45 & 617,73 & 991,01 & 276,09 & 57,07\end{array}$

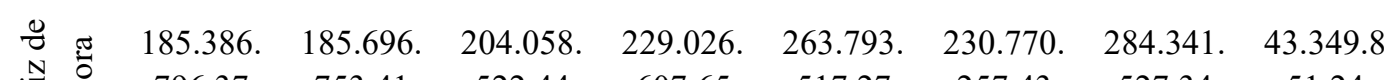

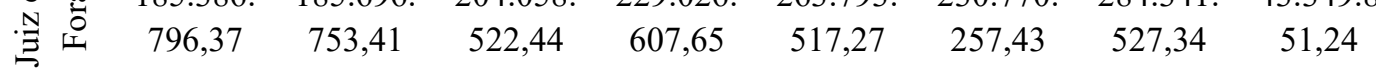

847.23

$5.648,3$

1.626.4

23.833, 15

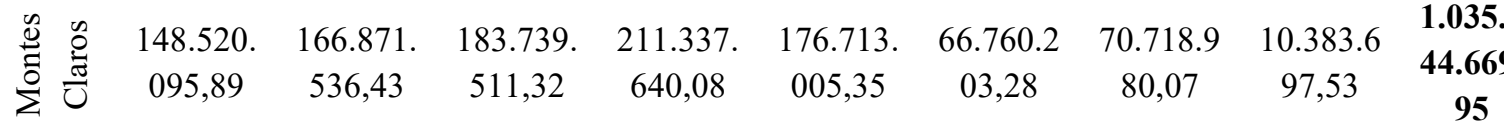

1.035 .0

44.669,

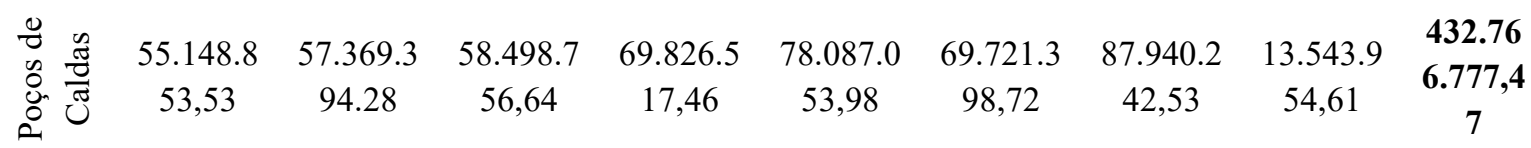

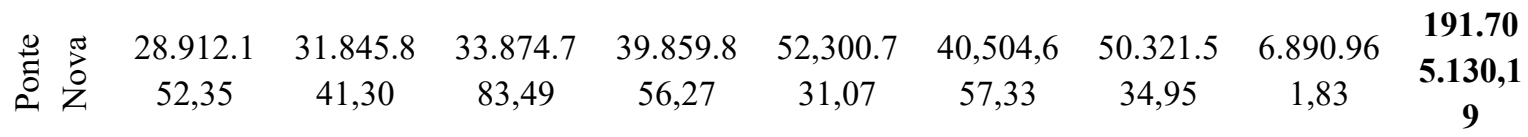

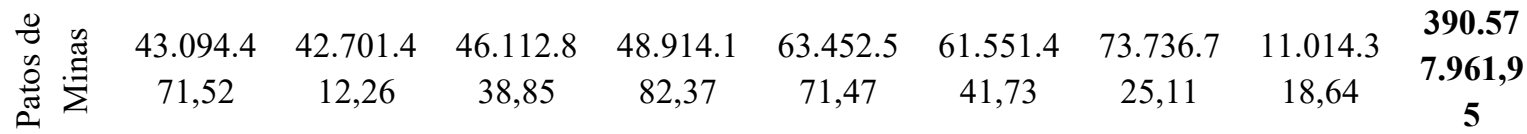

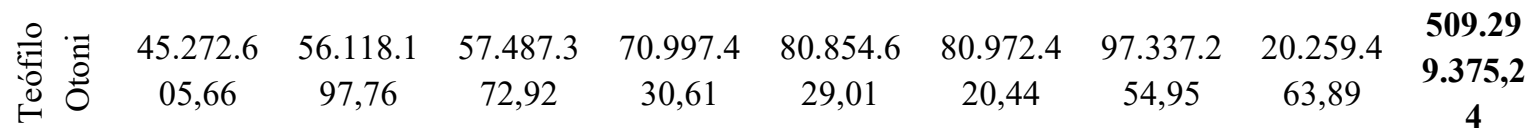

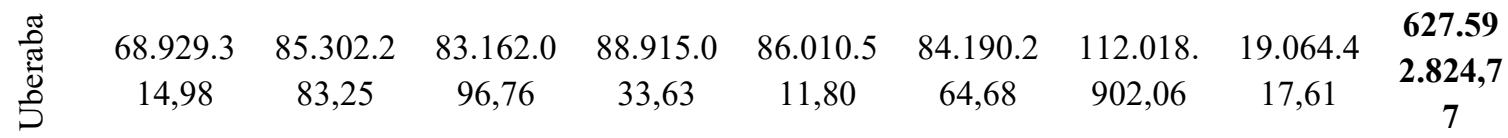

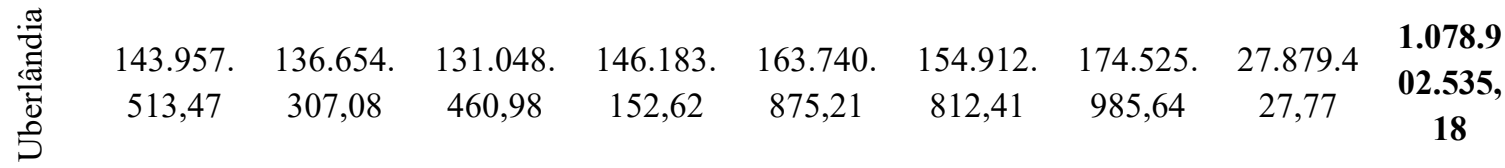

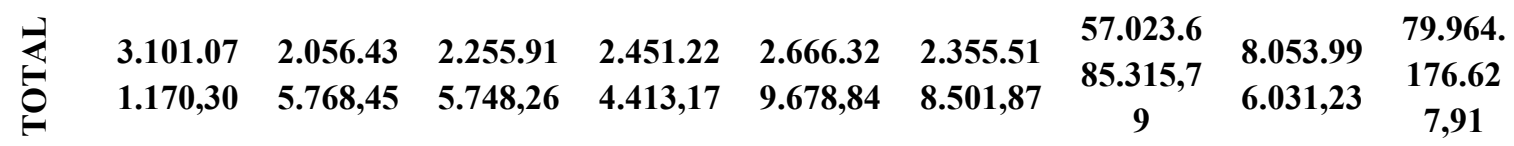

Fonte: Portal da Transparência e Ministério da Saúde, 2018. 
Para Avritzer (2009) os conselhos são resultados de diferentes negociações após o processo constituinte e um dos elementos que merece destaque é a relação entre a falta da participação e a penalidade, expressa na suspensão da transferência de recursos públicos federais para os municípios que não criarem os conselhos municipais de saúde. De forma complementar Gohn (2001) afirma que embora a criação dos conselhos tenha sido uma determinação legal para envio de repasse de recursos financeiros direto do Ministério da Saúde aos fundos municipais, ele também foi fruto da mobilização e luta popular para maior transparência e participação na gestão pública municipal.

A lei de criação estabelece que, cabe ao próprio conselho à elaboração de seu regimento interno bem como sua alteração, o que efetivamente ocorreu nos conselhos analisados. Assim, ainda que haja certa moldura colocada pela legislação, os conselhos têm liberdade, no âmbito do seu regimento, de alterar as suas regras de funcionamento e de seu processo deliberativo (CUNHA e THEODORO, 2015).

Desse modo, ao analisar em que ano o regimento interno em vigor foi criado, notou que, apesar dos conselhos terem sido criados no início da década de 90, seus regimentos datam o período entre 2007 e 2014. Para Almeida (2009), isto demonstra que os conselhos estão em constante mudança e em processo de reformulação de suas regras. A lei de criação estabelece que, cabe ao próprio conselho à elaboração de seu regimento interno bem como sua alteração, o que efetivamente ocorreu nos conselhos analisados. Assim, ainda que haja certa moldura colocada pela legislação, os conselhos têm liberdade, no âmbito do seu regimento, de alterar as suas regras de funcionamento e de seu processo deliberativo (CUNHA; THEODORO, 2015). Assim, ao analisar em que ano o regimento interno em vigor foi criado, notou que, apesar dos conselhos terem sido criados no início da década de 90, seus regimentos datam o período entre 2007 e 2016. Para Almeida (2009), isto demonstra que os conselhos estão em constante mudança e em processo de reformulação de suas regras.

Tal fato para Cunha e Theodoro (2015) faz com que os conselhos cumpram em alguma medida, com o princípio deliberativo da provisoriedade, que estabelece que as regras que organizam os espaços deliberativos devem ser passíveis de alteração pelos seus próprios participantes. Os dados ainda mostram que, dos conselhos analisados apenas quatro (Belo Horizonte, Governador Valadares, Juiz de Fora e Poços de Caldas) estão com o regimento adequado à legislação vigente vinculada à Resolução 453 de 2012. Em relação aos conselhos municipais de saúde de Diamantina, Montes Claros e Teófilo Otoni informações relacionadas ao regimento interno ainda não foram identificadas e analisadas devido à demora por parte destes conselhos em disponibilizar este tipo de informação. 


\subsection{ORGANIZAÇÃO INTERNA DOS CONSELHOS MUNICIPAIS DE SAÚDE}

$\mathrm{Na}$ análise do desenho institucional dos conselhos de saúde, conforme Quadro 3, foi verificada a quantidade de membros, a paridade entre eles, a frequência das reuniões e o tempo de mandato dos conselheiros e da mesa diretora.

Quadro 3 - Organização Interna dos Conselhos

\begin{tabular}{|l|c|c|c|c|}
\hline Conselho & $\begin{array}{c}\text { Número de } \\
\text { Membros }\end{array}$ & $\begin{array}{c}\text { Frequência de } \\
\text { Reunião }\end{array}$ & $\begin{array}{c}\text { Mandato dos } \\
\text { Conselheiros } \\
\text { (anos) }\end{array}$ & $\begin{array}{c}\text { Mandato da } \\
\text { Mesa } \\
\text { Diretora } \\
\text { (anos) }\end{array}$ \\
\hline Barbacena & 24 & Quinzenal & 2 & 2 \\
\hline Belo Horizonte & 40 & Mensal & 2 & 1 \\
\hline Divinópolis & 24 & Mensal & 4 & 3 \\
\hline Governador Valadares & 24 & Mensal & 2 & 2 \\
\hline Juiz de Fora & 54 & Quinzenal & 2 & 2 \\
\hline Patos de Minas & 20 & Mensal & 2 & 1 \\
\hline Poços de Caldas & 24 & Mensal & 2 & 2 \\
\hline Ponte Nova & 32 & Mensal & 4 & 2 \\
\hline Uberaba & 24 & Mensal & 4 & 1 \\
\hline Uberlândia & 32 & Mensal & 2 & 2 \\
\hline
\end{tabular}

Fonte: elaborado pelos autores com resultados da pesquisa, 2017/2018.

Em relação ao número de membros notou-se que varia consideravelmente, com o mínimo de 20 conselheiros em Patos de Minas e o máximo de 54 conselheiros em Juiz de Fora. É válido ressaltar que o porte do município não interfere no número de conselheiros, como se pode observar, pois, Belo Horizonte, considerado como município de grande porte e capital do estado mineiro possui 40 membros, ao passo que Juiz de Fora, município de médio porte, possui 54 conselheiros. Complementar à análise do número de membros, a pesquisa observou como se dá a divisão de cadeiras nos conselhos de acordo com os segmentos ali representados, na busca de aferir a presença de paridade. Para Almeida e Cunha (2011), a paridade é uma variável relevante, já que nos mostra como se dá a correlação de forças internamente ao conselho, ainda que a paridade não signifique igualdade.

De acordo com a Resolução $n^{\circ} 453$, o conselho de saúde é composto por representantes dos seguintes segmentos: usuários do SUS, trabalhadores de saúde, governo e prestadores de serviços de saúde, e as vagas devem ser distribuídas da seguinte forma: 50\% de entidades e movimentos representativos de usuários; $25 \%$ de entidades representativas dos trabalhadores 
da área de saúde; $25 \%$ de representação de governo e prestadores de serviços privados conveniados, ou sem fins lucrativos.

Os representantes do governo e gestão são indicados por seus superiores. Os representantes dos prestadores, trabalhadores e usuários tem que serem eleitos ou indicados delegados nas pré conferências ou reuniões especificas das categorias. Participam da assembleia para eleição dos conselheiros como delegados de seu segmento e é eleito conselheiro titular ou suplente pelos seus pares (ENTREVISTA 4 - SEGMENTO USUÁRIO, 2017).

No que se refere à frequência das reuniões ordinárias, a Resolução expõe que elas deverão ocorrer no mínimo uma vez ao mês, e extraordinariamente, conforme disposto em regimento interno, além de serem abertas ao público (BRASIL, 2012). Para Zambon e Ogata (2013) a periodicidade das reuniões garante a continuidade dos debates sobre os temas que estão sendo discutidos. Para as autoras, uma forma simples de verificar se um conselho funciona é identificar se as reuniões ocorrem de forma regular e averiguar se possui alguma estrutura administrativa. Corroborando com esta discussão, Carvalho (2007) aponta que a realização de reuniões é um indício de "vida orgânica dos conselhos", ou seja, é uma indicação direta do caráter ativo do conselho.

Assim, verificou-se que nesse item a diferença entre os conselhos analisados foi pequena e a maioria deles $(80 \%)$ realizam pelo menos uma reunião por mês. Apenas os conselhos de Barbacena e Juiz de Fora realizam reuniões quinzenalmente. É importante destacar que este número corresponde às reuniões ordinárias e, portanto, com caráter obrigatório. No entanto, a análise das atas das reuniões dos conselhos tem demonstrado que aqueles que realizam reunião mensalmente se reúnem em média duas vezes por mês, intercalando reuniões ordinárias e extraordinárias, já os conselhos que realizam reuniões quinzenalmente reúnem-se de três a quatro vezes por mês.

Para Aguiar (2016), a maioria dos conselhos pesquisados também prevê que as reuniões sejam abertas e públicas, somente os conselhos de Divinópolis e Governador Valadares que não trouxeram essa prerrogativa em seus regimentos. Já o conselho de Uberaba é o único que indica a possibilidade de ocorrer reuniões reservadas, desde que solicitadas por qualquer membro do conselho e aprovada por dois terços dos conselheiros presentes, algo que poderá induzir em restrição a informações e decisões inerentes aos Conselhos Municipais de Saúde. Quando as reuniões são abertas ao público e ocorrem em horário acessível, pode-se dizer que os conselhos cumprem com o princípio deliberativo da 
publicidade, uma vez que a deliberação ocorre em espaços públicos, que possibilitam a sua viabilidade e transparência.

Quanto à análise dos desenhos organizacionais dos conselhos, a Resolução n. $453 \mathrm{em}$ sua quarta diretriz coloca que "as três esferas de governo garantirão autonomia administrativa para o pleno funcionamento do conselho de saúde, dotação orçamentária, autonomia financeira e organização da secretaria-executiva com a necessária infraestrutura e apoio técnico" (BRASIL, 2012, p. 4). Assim ao verificar a estrutura que os conselhos apresentam observou-se que todos possuem a mesa diretora. Em geral, a mesa diretora é formada por um presidente, um vice-presidente, primeiro e segundo secretários e tem a função de coordenar as atividades do conselho e sua representação política junto à sociedade. Nos conselhos analisados essa estrutura é formada exclusivamente por conselheiros eleitos entre seus pares, o que indica a possibilidade de rotatividade entre os membros na ocupação desses cargos e a consequente democratização dos espaços decisórios. Outra estrutura importante nos conselhos são as comissões temáticas. Elas têm a função de elaborar análises e pareceres sobre temas, os quais serão submetidos ao plenário, propiciando aos seus membros a possibilidade de aprofundar os temas abordados, além de estimular e qualificar a atuação de seus membros (DAGNINO, 2002; ZAMBON; OGATA, 2011).

Todos os conselhos analisados têm esse espaço previsto de diferentes maneiras e com denominações diversas: comissões temáticas, câmaras técnicas, grupos de trabalhos e são vistos pelos conselheiros como importantes para a dinâmica das decisões. A influência e a importância da diretoria executiva e das comissões para o processo deliberativo foram evidenciadas nos depoimentos coletados para esta pesquisa, como pode observar em um dos relatos. Sobre esta discussão, foi perguntado como eles avaliavam a existência das câmaras técnicas e da secretaria executiva para o funcionamento do conselho. "As câmaras são importantíssimas, porque é por intermédio dela, do parecer das câmaras técnicas é que a plenária toma a decisão" (ENTREVISTA 8 - SEGMENTO USUÁRIO, 2017).

É valido ressaltar, que a presença dessa instância no regimento não garante que de fato ela se materialize no conselho e nem que funcionem de forma efetiva, assim, outros fatores devem ser considerados, como por exemplo, o perfil do conselho e a disponibilidade dos conselheiros, como mostram os depoimentos.

Depende um pouco do perfil. Hoje o secretário executivo é excelente, então funciona bem, também a composição das câmaras técnicas. Às vezes tem pessoas que tem menos tempo pra se dedicar, ele trabalha, o serviço dele não libera ele muito tempo, aí dificulta um pouco o 
trabalho das câmaras técnicas. Então, assim, eu acho que dentro do que é possível as câmaras são razoável, poderia ser melhor, mas nessa realidade é o que é possível para eles fazerem (ENTREVISTA 1 - SEGMENTO GOVERNO, 2017).

Nós temos problemas nessas áreas aí, justamente por causa da dificuldade, tem sempre uns conselheiros que participam mais, que tem mais disponibilidade, ai é, isso limita um pouco, porque né, nós não somos liberados pra isso né, então isso realmente é difícil, eu acho que nós já tivemos uma fase de mais reunião das comissões temáticas, então eu acho que isso ai é uma coisa que eu sinto que poderia está funcionando mais e melhor (ENTREVISTA 13 SEGMENTO USUÁRIO, 2018).

Embora tenha se verificado em todos os conselhos analisados a presença de comissões, essa não é uma realidade entre os conselhos brasileiros. Em estudo realizado em âmbito nacional, Carneiro (2006) verificou que somente 8,9\% dos conselhos municipais de saúde dispunham de comissões de caráter permanente e 3,73\%, de outros tipos de comissões. Verificou-se também se os conselhos analisados contavam com a presença de ouvidoria. A Resolução n. 453 não trás nenhuma exigência quanto a essa estrutura, assim cabe ao conselho definir sua existência ou não. Notou-se uma incidência pequena da ouvidoria nos conselhos, apenas Barbacena e Juiz de Fora que possuem esta instância.

Por fim, analisou-se a realização da conferência municipal de saúde, que, embora não seja uma estrutura dos conselhos, no entanto compõe o rol de suas competências. A Resolução n. 453 diz que cabe ao conselho estabelecer a periodicidade de convocação, organizar as conferências de saúde e convocar a sociedade para a participação nas préconferências e conferências de saúde (BRASIL, 2012). Assim, verificou-se que nove dos treze conselhos analisados (já que quatro ainda entrarão em fases posteriores da pesquisa) preveem a realização de conferências como uma de suas competências, destaque para o Conselho Municipal de Patos de Minas que tem um capítulo específico para tratar deste assunto. Já o conselho municipal de Governador Valadares foi o único que não se referiu à realização de conferência em seu regimento.

Para Almeida e Cunha (2011) a presença de estruturas organizacionais nos conselhos como mesa diretora, secretaria executiva, comissões técnicas e conferências é um bom indício da institucionalização e legitimação deste espaço, haja vista o papel destas estruturas na organização dos trabalhos e deliberações. De fato, notou-se claramente a importância 
dessas estruturas na institucionalização e na gestão dos conselhos, pois, durante o contato realizado para a execução desta pesquisa, verificou-se significativo acesso na obtenção das informações e os documentos necessários naqueles conselhos que possuíam uma estrutura que contava com a secretaria executiva, uma sede para o funcionamento, ao passo que, os conselhos que não possuíam essa estrutura, e em alguns casos o contato e acesso às informações foram dificultados como são os casos dos conselhos municipais de saúde de Diamantina, Montes Claros, Poços de Caldas e Teófilo Otoni.

Em relação ao processo deliberativo, entendido nas suas dimensões argumentativas e decisionais, existem diversas regras que estruturam o funcionamento dos conselhos e que pode indicar a abertura dada aos diferentes atores sociais presentes nas plenárias, em termos de possibilidade de proposição e introdução de pontos de pauta e das regras de tomada de decisão. Assim, nessa categoria foi analisada a forma de proposição de pauta, quem pode introduzir ponto de pauta, o direito de falas de atores externos e as formas de votação. De acordo com Almeida e Cunha (2011), a definição da pauta é uma etapa fundamental para o andamento das reuniões, tendo em vista que são os assuntos considerados relevantes, por parte de quem a define, que entram em discussão para votação em assembleia. Corroborando com esta discussão, Cunha e Theodoro (2015) e Aguiar (2016) ainda destacam em seus respectivos estudos a relevância dos temas que compõem a agenda, assim como seus propositores são fatores que indicam o potencial de inclusão e de democratização dos espaços.

A pesquisa também identificou como se dá a participação de atores externos no conselho, uma vez que estas pessoas têm o direito de participar das reuniões. De acordo com Aguiar (2016), se compreendermos a "voz" como uma ação política, a possibilidade de que outros atores falem e não somente os conselheiros, demonstra uma maior preocupação com a inclusão deliberativa dos interessados na política de saúde. Foi possível verificar nas entrevistas que, embora o conselho seja um espaço aberto a toda comunidade a participação ainda é muito tímida, e poucas pessoas participam das reuniões e até mesmo desconhece o conselho, como relatado pelos entrevistados. Desse modo, cabe a conselheiros e conselheiras pensarem em estratégias que possa aproximar o conselho da comunidade. Nas atas e nas entrevistas foi possível identificar algumas estratégias adotadas para que essa distância entre o conselho e a sociedade diminua. Algumas dessas estratégias são mais abrangentes e talvez mais impactantes como descrito nesse trecho retirado das atas analisadas.

A conselheira da UBS Brasil informou que distribuem convites das reuniões do conselho para as escolas, creches, instituições religiosas 
convidando a população para comparecerem nas reuniões e participarem. Estiveram nas rádios para convidarem a população. Elaboraram um folder e distribuíram para as comunidades explicando o que é o conselho, o nome dos conselheiros e seus telefones de contato, a fim de que os conselheiros se disponham a esclarecer os usuários de quaisquer dúvidas (ATA DO CMS DE UBERLÂNDIA, 2017).

No entanto, medida simples também demonstra a preocupação e o interesse do conselho para que a comunidade participe, como exposto por um entrevistado que exige que a porta onde ocorra as reuniões sempre esteja aberta.

[...] A gente estava aqui no salão, aqui em cima, às vezes quando vinha aquele vento frio, ai eles costumavam fechar a porta, eu falava não fecha, mas tá frio, não importa, porta de conselho não se fecha, não, mas deixa pelo menos uma gretinha, olha tem que deixar no mínimo a passagem para uma pessoa. [...] porque quando você fecha a porta de um conselho em reunião, você está fechando e coibindo a participação social. Porque, como um cidadão vai chegar aqui para participar se a porta está fechada, ele vai ter que bater? Então não pode, tem que deixar ela aberta, se ta aberta significa entra, é um convite, então eu sempre tenho batido nisso e eu tenho cobrado do conselho, não se fecha porta de conselho não. (ENTREVISTA 16 SEGMENTO USUÁRIO DO SUS, 2018).

Por fim, no que se refere à conclusividade da deliberação (COELHO, 2006; COHEN, 2009; MARQUES, 2010), foi analisado as formas de votação utilizadas nos conselhos. Assim, em $80 \%$ dos conselhos estudados a votação se dá por maioria simples. De acordo com Cunha e Theodoro (2015), tal fato pode ser interpretado positivamente, no que se refere à capacidade dos conselheiros chegarem a decisões, no entanto, este pode ser um ponto negativo para a representatividade se o conselho possui um número alto de membros não presentes nas reuniões, uma vez que as decisões serão tomadas sem levar em conta a proporção de todos os participantes desta instituição. Também se verificou que, entre os conselhos analisados, o conselho de Divinópolis decide por meio da maioria absoluta, já o conselho de Juiz de fora com um terço dos membros.

Normalmente, segundo os dados da pesquisa, as regras estabelecem que, após o conselho tomar uma decisão elas devem consubstanciar-se em resoluções, com exceção do 
conselho de Divinópolis que não trouxe nenhuma exigência sobre esta questão. As regras que estruturam a composição dos conselhos são relevantes por identificarem quais os atores que compartilham efetivamente o poder decisório, assim como, evidenciam possíveis restrições no acesso a esse espaço. Nesta perspectiva verificou-se que os critérios de composição das cadeiras dos conselhos variam de um para outro e podem ajudar a compreender a relação de representação via processo eleitoral que se estabelece entre conselheiros e suas instituições (AGUIAR, 2016).

Os representantes do governo e gestão são indicados por seus superiores. Os representantes dos prestadores, trabalhadores e usuários tem que serem eleitos ou indicados delegados nas préconferências ou reuniões especificas das categorias. Participam da assembleia para eleição dos conselheiros como delegados de seu segmento e é eleito conselheiro titular ou suplente pelos seus pares (ENTREVISTA 5 - SEGMENTO PROFISSIONAL DA SAÚDE, 2017).

Além da existência de processo eleitoral, os regimentos podem definir as categorias de segmentos que irão compor o conselho. A categoria refere-se às organizações ligadas a determinado tema. Neste caso, os regimentos só apontam a categoria que deve ter assento no conselho e não uma entidade específica, como por exemplo, instituições ligadas à determinada temática (ALMEIDA; CUNHA, 2011). Estes autores revelam ainda que outro meio de restringir ainda mais a participação de diferentes grupos no conselho é a definição prévia das entidades que terão direito de ter representantes no conselho. Para Aguiar (2016), a entidade prevista refere-se aos casos nos quais os conselhos indicam diretamente qual entidade terá direito a assento e representação. Como trás o regimento interno do conselho de Barbacena, "as vagas de conselheiros titulares e suplentes pertencem às entidades eleitas na Conferência Municipal de Saúde, só podendo ser substituídas em caso de extinção" (REGIMENTO INTERNO DO CONSELHO DE SAÚDE DE BARBACENA, 2017).

De acordo com Almeida e Cunha (2011), o alto número de entidades previstas nos conselhos de saúde é um indicador negativo, pois, ao definir as entidades que irão compor o conselho, a política de saúde deixa de ser capaz de incorporar possíveis mudanças na esfera pública, como por exemplo, o surgimento de novos movimentos sociais. A mesma autora ainda argumenta que o forte associativismo presente nesta área que abriu espaço e possibilidade para a participação social, também esteja sendo responsável por não "abrir mão" de sua representação nos conselhos. Embora, reconheça que a participação de antigos 
participantes no conselho é importante para o aprendizado dos novos, acredita que ela pode acabar com as possibilidades de renovação e influência de diferentes segmentos. Corroborando com esta afirmativa tem-se que:

[...] ao mesmo tempo em que tem conselheiros não atuantes, há uma minoria experiente e capacitada que consegue intervir nas discussões de planejamento e execução de políticas de saúde e de ações. Inclusive na elaboração da Agenda de Saúde, Plano Plurianual e Proposta Orçamentária Anual. Quando não somos atendidos recorremos ao Ministério Público, Vereadores e mídia (ENTREVISTA 21- SEGMENTO USUÁRIO, 2018).

Outra característica importante na estruturação dos conselhos municipais de saúde está relacionada com a escolha do presidente (AGUIAR, 2016). Embora a lei de criação e os regimentos dos conselhos restrinjam formalmente as atribuições do presidente, na prática, em muitos casos o presidente assume papéis estratégicos como pode ser percebido na entrevista a seguir.

A Mesa Diretora se reúne uma vez por semana antes da reunião, define a pauta com os assuntos a serem deliberados na reunião ordinária e encaminha a pauta, juntamente com a convocação, sete dias antes da reunião via email. São encaminhadas juntamente a documentação sobre o assunto em pauta, para conhecimento e análise prévia dos conselheiros, durante este periodo pré reunião a câmara técnica responsável pelo assunto em pauta se reúne analisa e emite relatório técnico sobre o assunto que é apresentado ao plenário do Conselho durante a reunião ordinária, após esta apresentação os conselheiros e demais participantes tem direito à fala e após as mesmas o assunto é colocado para votação dos conselheiros titulares (ENTREVISTA 6 - SEGMENTO GOVERNO, 2017).

Assim, a importância da função do presidente foi identificada por Tatagiba (2002) e Faria e Ribeiro (2011), já que em muitos dos conselhos é ele que define os temas que tenham prioridade na agenda e será pautado. Ademais, a forma como ele é escolhido mostra o grau de democratização das relações no interior dessas instituições. Portanto, a forma de escolha do presidente é importante para aferir o grau de democratização desses conselhos.

Faria e Ribeiro (2011) sinalizam para um fato recorrente nos conselhos de saúde, que é a indicação do secretário municipal de saúde para ocupar o cargo de presidente do conselho. 
De acordo com as autoras esse fato além de ferir o princípio representativo indica monopólio do cargo pelo representante do governo, configurando o predomínio desse segmento frente aos demais segmentos que compõem o conselho. Embora a presença do secretário municipal ou de seus representantes seja necessário para a dinâmica de negociação e implementação das diretrizes da política pública, de acordo com Faria e Ribeiro (2011) esta naturalização precisa ser revista. Apesar de Faria e Ribeiro (2011) terem explanado este cenário, nos conselhos analisados não foi encontrada essa situação, no entanto, percebeu-se que essa é uma conquista recente, como descrita nessa passagem em uma das atas analisadas;

E.R: pede a palavra para parabenizar a nova mesa diretora e fala das conquistas do conselho de hoje ser conduzido por um usuário que antes era sempre representado por médicos ou políticos, dizendo que foi um avanço muito grande na democratização (ATA DO CMS DE BARBACENA, 2017).

Notou-se também que embora o secretário de saúde não seja presidente do conselho, sua presença é forte. Muitas vezes ele é o responsável por conduzir as reuniões, o que faz com que assuntos de seu interesse sejam colocados em evidência nas discussões, além de influenciar ou mesmo manipular decisões, devido seu conhecimento sobre o assunto.

[...] o secretário, a secretária adjunta $M$, eles põe em pauta os projetos que precisa apresentar pros conselheiros e até mesmo as outras coisas a mais que eles ficam sabendo eles levam sempre pro conselho pra poder passar para todos os conselheiros, pra que todos os conselheiros fique sabendo daquilo que está acontecendo. E tudo que tem que ser votado também, primeiro passa, é... eles "zipa" aquilo pra depois vê se o conselho vai aprovar ou não (ENTREVISTA 20 - SEGMENTO USUÁRIO, 2018)

Ademais, a relação do secretário com o conselho pode indicar a importância que a administração pública dá para esse espaço e a efetividade das suas ações.

A relação do secretário municipal de saúde com o conselho depende de mandato e de gestão, ás vezes tem um secretário que ele é mais aberto, às vezes tem um mais fechado, quando é um mais aberto a gente tem uma boa relação, mas quando é um mais fechado a relação fica um pouco mais dificultada (ENTREVISTA 16 - SEGMENTO USUÁRIO, 2018). 
Porque a secretária municipal parece que ela não gosta do conselho não, o conselho para ela é uma pedra no caminho dela. [...] Muitas vezes ela toma a decisão por conta própria dela e quer que o conselho aceite do jeitinho dela, nossa, quando fala que vai avaliar uma coisa que ela decidiu, nossa, ela fica brava demais. [...] o secretário anterior dela, ele sim, ele era compreensível, era parceiro do conselho, isso é muito, muito importante, já essa secretária agora, ela é totalmente contra o conselho (ENTREVISTA 10 SEGMENTO PROFISSIONAL DA SAÚDE, 2017).

Em relação a quem pode propor mudanças no regimento interno, em todos os casos em que constava tal informação, são os próprios conselheiros responsáveis por alterações neste documento. Os conselhos apenas diferem em relação à necessidade de proporção de conselheiros para aprovação e proposição.

\section{CONSIDERAÇÕES FINAIS}

A reestruturação normativa, representada nas leis e nos regimentos internos dos conselhos municipais de saúde, parece corresponder à própria condição de inovação institucional desses espaços, muitos deles, criados a partir da indução dos governos federal e estadual e que precisaram adequar suas regras à realidade local ou em muitos casos, a própria legislação e normas federais (CUNHA; THEODORO, 2015). Assim, verificou-se que há muita semelhança nas regras dos conselhos em análise, talvez em decorrência do próprio processo histórico de indução da criação dessas instituições.

Surge então a partir de meados do século XX, o Movimento da Reforma Sanitária, que reuniu sanitaristas, intelectuais e diversos atores sociais em prol de uma batalha política pelo reconhecimento da saúde como direito social, pela universalização do acesso aos serviços de saúde e pela integralidade da atenção a saúde. Ocorre também nessa época, a VIII Conferência Nacional de Saúde, que se constituiu em um marco na história da saúde no Brasil, pois, foi durante essa conferência que se definiu as diretrizes e os princípios básicos sobre os quais o Sistema Único de Saúde (SUS) deveria ser legitimado e institucionalizado, sendo os princípios, a universalização da cobertura e do atendimento, a descentralização das ações e serviços, e a equidade no acesso aos mesmos. Dentre as diretrizes estão o atendimento integral, a participação da comunidade no controle social, a descentralização das ações e serviços com a direção única em cada esfera do governo (BRASIL, 1988). 
Dessa forma, a análise das regras de funcionamento dos Conselhos Municipais de Saúde, pertencentes às macrorregiões de planejamento em Saúde do Estado de Minas Gerais, nos indica que eles estão em processo de mudança e renovação e, portanto, como colocado por Almeida e Cunha (2011), estão bem diferentes das instituições criadas na década de 1990. Tal fato pode ser confirmado pelas constantes mudanças no regimento interno da maioria dos conselhos pesquisados, sinalizando tendências de adaptações e acompanhamento das mudanças contextuais e legais. Desde a sua institucionalização, os conselhos passaram a ser objeto de análise de várias pesquisas que buscavam compreender a atuação desses espaços.

Nesse sentido, tem-se que a primeira fase dos estudos revistos para fundamentação deste artigo, preocupou em analisar a correlação entre a participação dos cidadãos nos espaços públicos e o aprofundamento da democracia. Nessa fase, o pressuposto era de que a participação levaria ao aprendizado democrático. $\mathrm{Na}$ segunda fase, buscou-se investigar fatores que pudessem influenciar a eficiência desses espaços participativos, o que implicou na análise do sucesso ou insucesso dos conselhos. Hoje, a agenda de pesquisa está concentrada principalmente na análise da efetividade deliberativa, da representatividade e do desenho institucional desses espaços.

Do conhecimento acumulado desses estudos, as evidências empíricas têm mostrado diversas limitações enfrentadas por esse espaço de participação social, dentre as mais comuns, a assimetria informacional, a imposição dos gestores públicos nas decisões, a manipulação política, estão à falta de capacitação dos seus membros, dentre outras. No contexto de multicasos analisados nesta pesquisa, os resultados indicam que o desenho institucional dos conselhos impactou de forma positiva o processo deliberativo, pois, permitiu maior abertura à participação da sociedade civil e um melhor equilíbrio entre a presença dos atores governamentais e não governamentais, pelo menos no que diz respeito às regras de funcionamento. Pode-se confirmar que tal constatação é percebida nas regras referentes ao cargo da presidência, à proposição e introdução de pontos de pauta, à possibilidade de fala de atores externos e à presença de paridade entre os segmentos.

Também se constatou que à estrutura dos conselhos e a dinâmica de suas atividades, na maioria dos conselhos analisados, está em plena atividade com a periodicidade de reuniões, possuem estrutura administrativa como mesa diretora, secretaria executiva e câmaras técnicas, estruturas essas que auxiliam na qualificação dos atores sociais para a participação no processo deliberativo. Portanto, pode-se inferir que os conselhos de saúde analisados são instituições que apresentam uma boa capacidade de desenvolvimento de suas atividades administrativas e participativas. 
Com isso, chega-se a conclusão de que os conselhos de saúde constituem uma inovação institucional essencial no campo da saúde pública, principalmente, no que se refere ao espaço de formulação e implementação das políticas públicas de saúde na esfera municipal. No entanto, outras análises devem ser levadas em consideração, para que seja observado se na prática do cotidiano dos conselhos, as regras e as normas que os estruturam são de fato seguidas.

\section{REFERÊNCIAS}

ABERS, R. N. Inventing local democracy: grassroots politics in Brazil. Boulder: Lynne Rienner Publishers, July, 1, 2000.

AGUIAR, C. C. de. Participação e deliberação no processo decisório dos conselhos gestores de políticas públicas em saúde de Minas Gerais. Viçosa/MG: UFV, 2016. Originalmente apresentada como dissertação mestrado em Administração, Universidade Federal de Viçosa, 2016.

AGUIAR, C. C. de; SILVA, E. A.; FERREIRA, M. A. M. Os efeitos das instituições participativas sobre a gestão pública municipal. In: II ENCONTRO INTERNACIONAL SOBRE PARTICIPAÇÃO, DEMOCRACIA E POLÍTICAS PÚBLICAS. 2015, Campinas. Anais. Campinas: UNICAMP, 2015, p. 1-22.

ALMEIDA, D. C. R. de A.; CUNHA, E. S. M. A análise da deliberação democrática: princípios, conceitos e variáveis relevantes. Brasília, DF: IPEA, 2011.

AVRITZER, L. Instituições participativas e desenho institucional: algumas considerações sobre a variação da participação no Brasil democrático. Opinião Publica, Campinas, v.14, n. 1, p. 43-64, junho, 2008.

AVRITZER, L. Participatory institutions in democratic Brazil. Baltimore: Johns Hopkins University Press, 2009.

BARDIN, L. Análise de conteúdo. Lisboa: Edições 70, 2011.

BRASIL. Senado Federal. Constituição Federal. Brasília, DF: Senado Federal, 1988.

BRASIL. Lei no 8142, de 28 de dezembro de 1990. di. Diário Oficial [da] República

Federativa do Brasil, Poder Executivo, Brasília, DF, 31 dez., 1990. Seção 1, p. 25694.

BRASIL, F. de P. D.; CARNEIRO, R.; BARBOSA, T. P.; ALMEIDA, M. E. Participação, Desenho Institucional e Alcances Democráticos: uma Análise do Conselho das Cidades (CONCIDADES). Revista de Sociologia e Política. Curitiba, v. 21, n. 48, p. 5-18, dez. 2013. 
BRUYNE, P.; HERMAN, J.; SCHOUTHEETE, M. Dinâmica da pesquisa em ciências sociais: os polos da prática metodológica. Rio de Janeiro: Francisco Alves Editora, 1991.

CARNEIRO, C. B. L. Conselhos de políticas públicas: desafios para sua institucionalização. Brasília, DF: ENAP, 2006.

CARVALHO, G. C. M. Participação da comunidade na saúde. Passo Fundo: IFIBE, 2007. COELHO, V. S. P. Democratization of Brazilian health councils: the paradox of bringing the other side into the tent. International Journal of Urban and Regional Research. University of Cambridge, 16 October, v. 30, n.3, 2006, p. 656-671.

COELHO, V.S. R. P. Conselhos de saúde enquanto instituições políticas. São Paulo: 34 Letras, 2004.

COHEN, J. Deliberação e legitimidade democrática. Belo Horizonte: Autêntica Editora, 2009.

CUNHA, E. S. M.; THEODORO, H. D. Desenho institucional, democracia e participação: conexões teóricas e possibilidades analíticas. Belo Horizonte: D’Plácido, 2015.

DAGNINO, E. Sociedade civil e espaços públicos no Brasil. São Paulo: Paz e Terra, 2002.

DAHL, R. Democracy and its critics. New Haven: Yale University Press, 1989.

FALEIROS, V. P.; SENNA DA SILVA, J. F.; VASCONCELLOS, L. C. F., SILVEIRA, R. M. G. A construção do SUS. Brasília, DF: Ministério da Saúde, 2006.

FARIA, C. F. Democracia deliberativa: Habermas, Cohen e Bohman. Lua Nova: Revista de Cultura e Política, São Paulo, n. 50, p. 47-68, 2000.

FARIA, C. F.; RIBEIRO, U. C. Desenho institucional: variáveis relevantes e seus efeitos sobre o processo participativo. Brasília, DF: IPEA, 2011.

FEDOZZI, L. Esfera pública e cidadania: a experiência do orçamento participativo de Porto Alegre. Ensaios FEE, Porto Alegre, v. 19, n. 2, p. 236-271, 1998.

FLEURY, S.; OUVERNEY, A. S. M.; KRONEMBERGER, T. S.; ZANI, F. B. Governança local no sistema descentralizado de saúde no Brasil. Revista Panamericana de Salud Pública, Washington/USA: v. 28, n. 6, p. 446-55, 2010.

FUKS, M.; PERISSINOTTO, R. M.; SOUZA, N.R. (Org.). Democracia e participação: os conselhos gestores do Paraná. Curitiba: Editora da UFPR, 2004.

FUNG, A. Empowered participation: reinveting urban democracy. Princeton: Princeton University Press, 2004.

GIL, A. C. Métodos e técnicas de pesquisa social. 5. ed. São Paulo: Atlas, 2007. GODOY, A. S. Pesquisa qualitativa: tipos fundamentais. Revista de Administração de Empresas, São Paulo, v. 35, n. 3, p. 20-29, mai/jun, 1995. 
GOHN, M. G. Conselhos gestores e participação política. São Paulo: Cortez, 2001.

HABERMAS, J. Três modelos normativos de democracia. Lua Nova: Revista de Cultura e Política, São Paulo, v. 36, p. 39-53, 1995.

HUNTINGTON, S. A. A Terceira Onda: a democratização no final do século XX. São Paulo: Ática, 1994.

INSTITUTO BRASILEIRO DE GEOGRAFIA E ESTATÍSTICA. Perfil dos municípios brasileiros. Pesquisa básica de informações municipais (Munic). Rio de Janeiro: IBGE, 2015.

JACOBI, P. Descentralização municipal e participação dos cidadãos: apontamentos para o debate. Lua Nova: Revista de Cultura e Política, Rio de Janeiro, v. 20, p. 121-144, 1990. LIMA, N. T.; GERSCHMAN, S.; EDLER, F. C.; SUÁREZ, J. M. Saúde e democracia: história e perspectivas do SUS. Rio de Janeiro: Editora Fiocruz, 2005.

LIMA, P. G. O desenho institucional e as instituições participativas: conselhos gestores de políticas públicas e orçamentos participativos. Revista Contraponto, Porto Alegre, vol., $1 \mathrm{n}$. 1, jan/jul, 2014.

MARQUES, F. P. J. A. Participação política e desenho institucional: uma proposta para a concepção de mecanismos participativos. Ciências Sociais Unisinos, São Leopoldo, v. 46, n. 2, p.140-151, mai/ago, 2010.

O’DONNELL, G. Delegative democracy. Journal of democracy. 5. ed.

Baltimore/Maryland/USA: The Johns Hopkins University Press, n 1, p. 55-69, January, 1994. PATEMAN, C. Participation and democratic theory. 20 ed. New York: Cambridge University Press, 1999.

PUTNAM, R. Making Democracy Work: Civic Traditions in Modern Italy. Princeton/New Jersey/USA: Princeton Unversity Press, 1993.

SILVA, E. A; LOPES, B. de J; OLIVEIRA, A. R.; MARTINS, S. Conselhos de saúde: funcionamento, participação e compartilhamento da gestão. In: CONGRESO INTERNACIONAL DEL CLAD SOBRE LA REFORMA DEL ESTADO Y DE LA ADMINISTRACIÓN PÚBLICA. 2014, Quito. Anais. Quito: Ecuador, 2014.

TATAGIBA, L. A institucionalização da participação: os conselhos municipais de políticas públicas na cidade de São Paulo. São Paulo: Editora da UNESP, 2004.

VERGARA, S. C. Métodos de pesquisa em administração. 6. ed. São Paulo: Atlas, 2015. ZAMBON, V. D.; OGATA, M. N. Controle social do Sistema Único de Saúde: o que pensam os conselheiros municipais de saúde. Revista Brasileira de Enfermagem, Brasília, DF, novdez; v. 66, n. 6, p. 921-927, nov/dez, 2013. 
WENDHAUSEN, A.; CARDOSO, S. M. Processo decisório e Conselhos Gestores de Saúde: aproximações teóricas. Revista Brasileira de Enfermagem, Brasília, DF, v. 60, n. 5, p. 579584, set/out, 2007. 